\title{
Development of a Formalized Scheme of Hydrocarbon Transformations in the Catalytic Cracking for Forecasting the Individual Composition of Gases
}

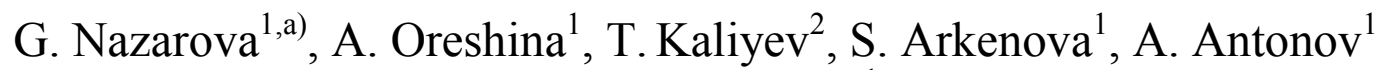 \\ and E. Lemeshko \\ ${ }^{1}$ National Research Tomsk Polytechnic University, 30 Lenina avenue, Tomsk 634050, Russian Federation \\ ${ }^{2}$ S. Toraighyrov Pavlodar State University, 64 Lomov St., Pavlodar 140008, Kazakhstan \\ ${ }^{\text {a) }}$ Corresponding author: $\underline{\text { silko@tpu.ru }}$
}

\begin{abstract}
The work aims to create a formalized scheme of the hydrocarbons transformation in the catalytic cracking with the participation of high-molecular hydrocarbons of vacuum distillate in order to predict the gasoline group composition and the gases individual composition. Thermodynamic parameters of the most probable reactions of cracking gases formation under technological conditions of the process using the reference data and Density Functional Theory are determined; the features of the mechanism of hydrocarbon transformations on acid catalysts determining the high content of isoalkanes, alkenes, aromatic hydrocarbons in cracking products are taken into account.
\end{abstract}

\section{INTRODUCTION}

Today, methods of mathematical modeling are widely used to solve interrelated and multi-factor problems of prediction of the composition and properties of products and optimizing industrial processes of oil refining [1-3]. Since the processes of oil refining are multi-component and many chemical reactions take place on the surface of catalysts, the models developed are based on the formalized reactant conversion schemes.

Development of a formalized scheme of hydrocarbon transformation in oil refining processes is the most important stage determining the prediction ability of the model to solve the required production tasks (prediction of the composition and yield of the gasoline, diesel fraction, gases, etc.) and providing a high model adequacy.

There are different approaches to the formalization of chemical transformations in the process of catalytic cracking, depending on the sensitivity of laboratory methods and the required predictive power. The approach to catalytic cracking modeling is mainly realized by forming pseudo-components of a wide fractional composition and coke $[1,2,4]$. There are 4-, 5-, 6-, 11-component schemes for boiling temperatures, the unit streams with a separate regeneration stage, etc. [5-7], since the modeling of deep processing of oil raw materials is complicated by the difficulty of identifying the hydrocarbon composition of heavy fractions $\left(350-570+{ }^{\circ} \mathrm{C}\right)$. This approach allows determining the weight share of pseudo-components of a wide fractional composition, but does not consider the reaction capacity of hydrocarbons inside the selected groups and the group characteristics of the processed raw materials, while the hydrocarbon composition of each pseudo-component is diverse [8]. Although with the increase in the boiling point of the raw materials of catalytic cracking, the content of coke on the catalyst increases, as well as the content of aromatic and resinous compounds [9], this approach does not take into account the coke formation as a result of consecutive bimolecular reactions involving hydrocarbons of various groups (condensation, diene synthesis, hydrogen transfer, etc.). The hydrocarbon composition significantly affects the output of coke and the deactivation of catalysts, causing loss of their operational properties, the output and composition of products, which must be considered in the modeling of the process.

Another approach using combined models involves not only interaction of pseudo-components, but also chemical transformations of major hydrocarbon groups of raw-stream installations of catalytic cracking (alkanes, cycloalkanes, arenas, substituted arenas for light and heavy fractions of oil, as well as groups of coke + gas and gasoline) [10-12]. This approach is characterized by information about the reaction mechanism with the average reaction capacity of hydrocarbon groups. This allows prediction of the raw materials conversion; the group

Oil and Gas Engineering (OGE-2020)

AIP Conf. Proc. 2285, 020014-1-020014-8; https://doi.org/10.1063/5.0026683

Published by AIP Publishing. 978-0-7354-4015-9/\$30.00

020014-1 
composition of cracking products, the yield of light fractions, gas and coke, which in its turn allows the degree of catalyst deactivation to be estimated from a large number of factors of the catalytic cracking. Combined and flow schemes of hydrocarbon transformation in the process of catalytic cracking are improved by dividing the components of the system into various reaction groups, introducing the mechanisms of accounting for coke deposits on the catalyst, etc. [13]. Thus, for example, the authors [14, 15] introduced the division of raw materials into resins, asphaltenes, saturated and aromatic hydrocarbons in the scheme, as well as the separation of coke formation stage into two stages of gas formation. Detailed description of chemical transformations of hydrocarbons in the catalytic cracking, taking into account the composition of the catalyst and the prediction of the coke content on the catalyst surface, is performed in $[16,17]$.

Another focus of the process, driven by a growing demand in cracking gases as petrochemical raw material, when expanding the production of alkylates, esters, polymerizates, high-quality gasoline, causes the relevance of predicting the composition of cracking gases depending on many aspects. They are a large number of parameters of the technological regime, the composition of raw materials, the deactivation of catalysts, and optimization of conjugated multi-stage processes of oil refining and petrochemistry. This problem is particularly relevant for units integrated in petrochemical plants.

However, there are limited studies in the literature about modeling the catalytic cracking process based on a hydrocarbon conversion scheme, focused on predicting the individual composition of cracking gases, the group composition of the gasoline fraction, and coke. Thus, in [18] the model is based on a formalized scheme involving pseudocomponents of a wide fractional composition (vacuum gas oil, gasoline, coke 1, coke-2), as well as light olefins - ethylene and propylene. Moreover, it does not consider the hydrocarbons composition of the raw material and does not allow predicting the content of such components as isobutane and alkenes of $\mathrm{C} 4$, whose content in the butane-butylene fraction is approximately $40 \%$ wt. The work [19] calculates the content of 1, 3-butadiene and butylenes formed in the FCC process, ignoring the conversion of gas oil to isobutane (BPF content about $40 \%$ by weight), n-butane, methane (dry gas content more than $20 \% \mathrm{wt}$ ).

Thus, the creation of a mathematical model suitable for predicting the content of gasoline-type hydrocarbons and cracking gases is relevant both from the point of view of optimizing gasoline compounding processes and petrochemical treatment of raw materials. In order to create such a model, it is necessary to formalize the hydrocarbon conversion scheme according to its molecular weight, taking into account the formation of individual cracking gas compounds. In the step of forming the hydrocarbon conversion scheme, a thermodynamic analysis of the process reactions is required to evaluate the reactivity of the hydrocarbons and the principle feasibility of the reactions under process conditions $\left(\Delta \mathrm{rG}^{\mathrm{o}}{ }_{810}<0\right)$.

The aim of the work is to develop a formalized hydrocarbon conversion scheme in a catalytic cracking focused on predicting the gasoline group composition and the individual composition of the cracking gases.

\section{EXPERIMENTAL}

\section{Object and Methods}

The study subject is the industrial process of catalytic cracking (Fig. 1).

The technology of catalytic cracking is implemented as a part of a combined unit designed for deep processing of fuel oil in the fuel version of KT-1/1 at section C-200. Catalytic cracking process feedstock is vacuum distillate product of vacuum distillation of fuel oil (section C-001) followed by hydrotreating (section C-100).

Individual composition of gasoline fraction was determined according to Russian National Standard GOST R 52714-2007 "Determination of individual and group hydrocarbon composition by capillary gas chromatography" for determination of hydrocarbon composition of gasoline of catalytic cracking process using gas chromatograph "CHROMATEK-CRYSTAL 5000" 2 version with flame ionization detector, "Chromatek Analyst" software, capillary column DV -1, $100 \cdot 0.25 \cdot 0.5$ ).

Quantum-chemical methods of calculating electronic structure of molecules are used for investigation of thermodynamic parameters of catalytic cracking reactions when the hydrocarbons are absent in the reference data [20]. 


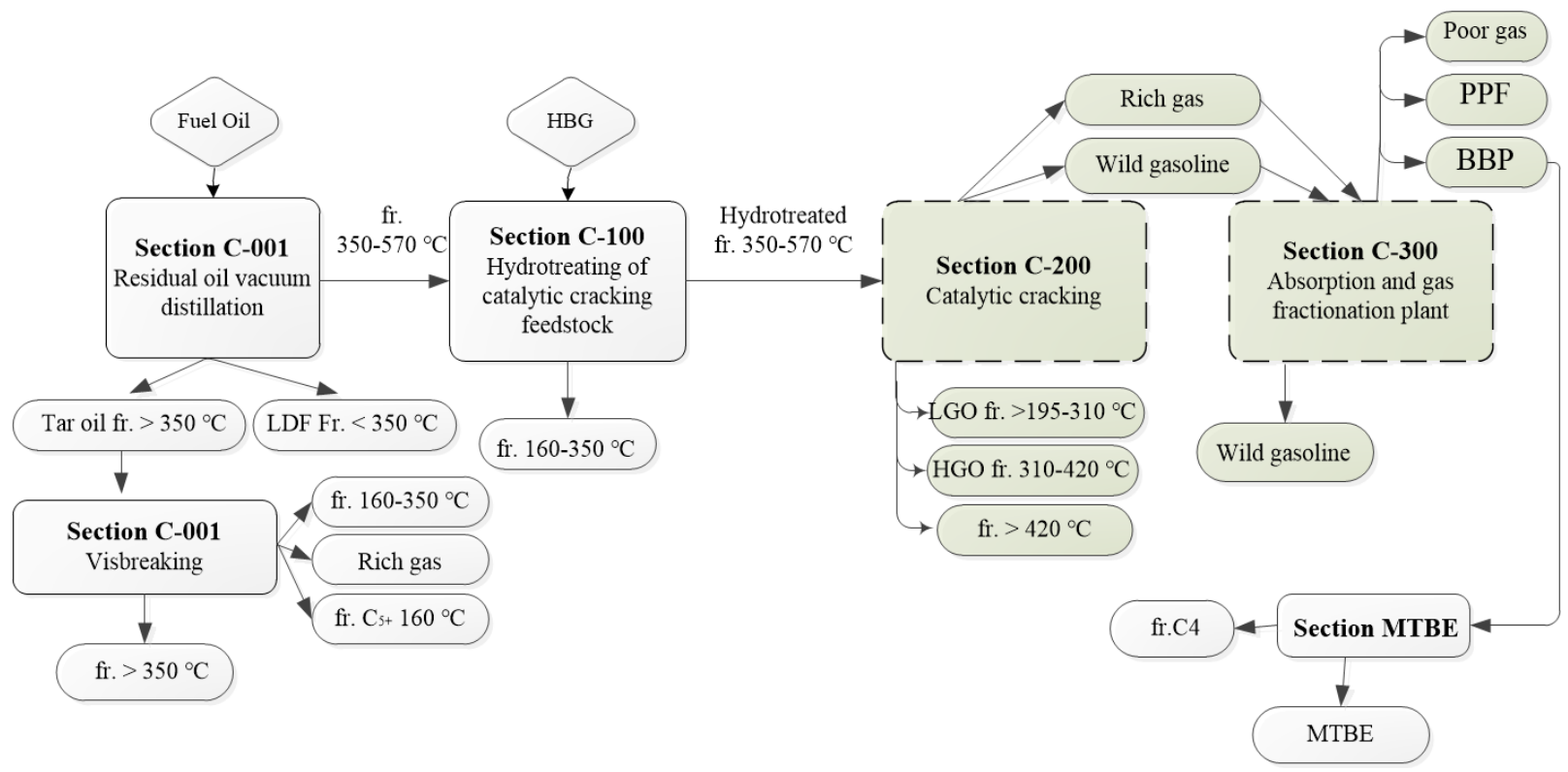

FIGURE 1. Simplified diagram of combined fuel oil deep processing unit according to fuel version of KT-1/1, here HBG hydrogen-bearing gas, LDF - light distillation fraction, LGO - light gas oil, HGO - heavy gas oil, MTBE - methyl-tret-butylether, PPF - propane-propylene fraction, BBP - butyl benzyl phthalate.

\section{RESULTS AND DISCUSSION}

The primary and secondary reactions of the catalytic cracking process were recorded with the participation of hydrocarbons of raw materials (Table 1) and products (Table 2)established experimentally with the application of gas and liquid chromatography methods, structural-group analysis, etc. [21,22].

TABLE 1. Characteristics of feedstock hydrocarbon groups involved in the catalytic cracking process.

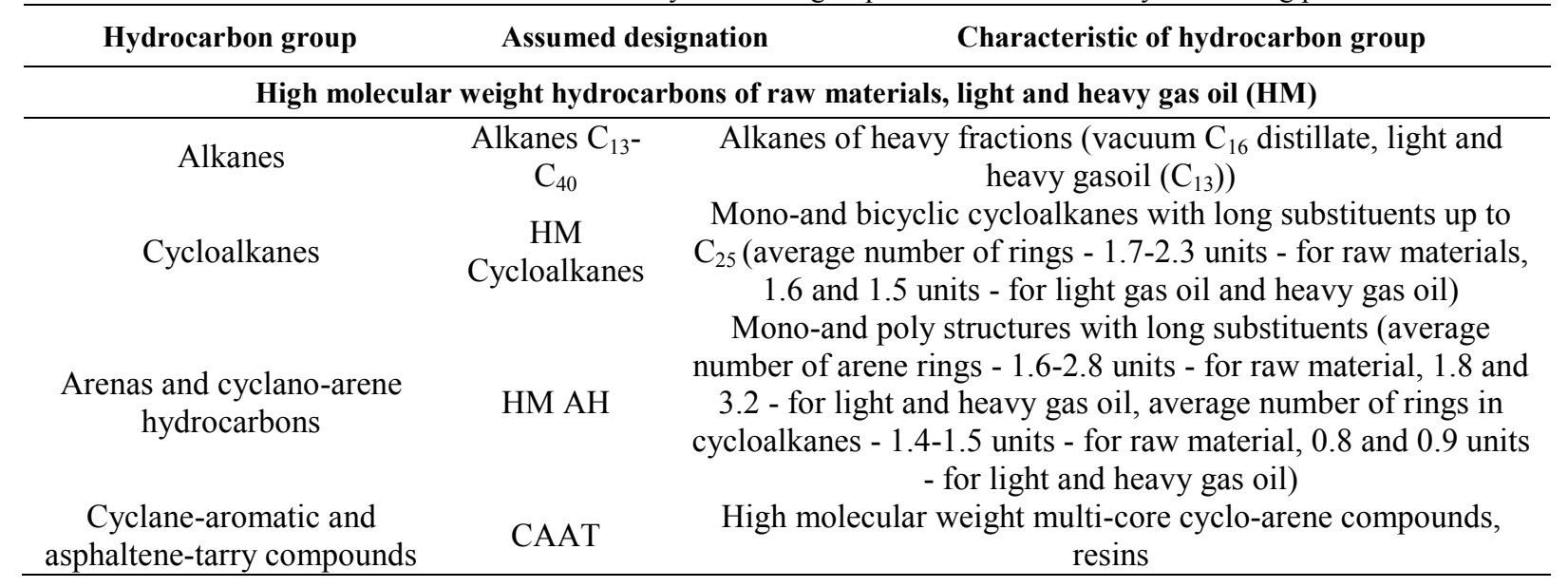

When recording reactions, the mechanism of hydrocarbons transformation in the process of catalytic cracking and the carbocations stability was taken into account. The hydrocarbon conversion mechanism in the catalytic cracking process provides a high content of isoalkanes, alkenes and arenes in the gasoline fraction as well as propylene, isobutane and butylenes in the cracking gases (Table 3). 
TABLE 2. Characteristics of hydrocarbon groups of the catalytic cracking products.

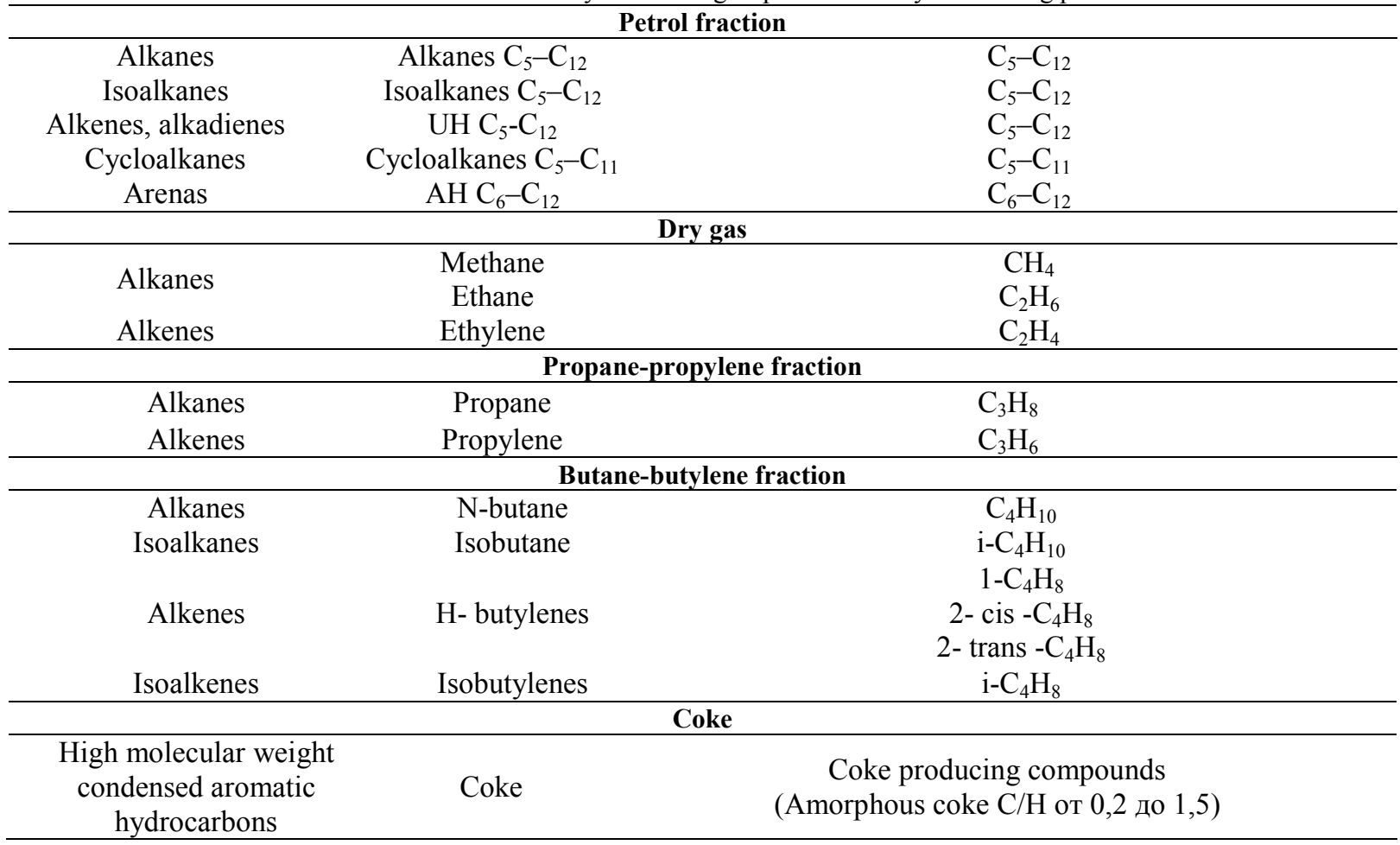

TABLE 3. Components of gasoline fraction and cracking gases.

\begin{tabular}{|c|c|c|c|c|c|}
\hline \multicolumn{6}{|c|}{ Content in gasoline fraction } \\
\hline $\mathrm{N}$-alkanes and alkenes & $\% \mathrm{wt}$ & Isoalkanes and cycloalkanes & $\% \mathrm{wt}$ & Arenas & $\% \mathrm{wt}$ \\
\hline \multirow{5}{*}{$\begin{array}{l}\text { n-pentane } \\
\text { n-hexane } \\
\text { n-heptane }\end{array}$} & \multirow[b]{3}{*}{1.29} & isopentane & 11.15 & \multirow{2}{*}{ Benzene } & \multirow{2}{*}{0.80} \\
\hline & & 2-methylbutene & 1.69 & & \\
\hline & & dimethylbutane & 1.09 & Toluene & 3.62 \\
\hline & 1.03 & dimethylbutane & 1.07 & Ethylbenzene & 1.04 \\
\hline & 0.66 & 2- methylpentane & 4.90 & 1,3-dimethylbenzene & 3.12 \\
\hline n-octane & 0.46 & 3- methylpentane & 3.11 & 1,4-dimethylbenzene & 1.16 \\
\hline trans-butene-2 & 0.44 & 2- methylpentane & 0.53 & 1,2- dimethylbenzene & 1.51 \\
\hline c-butene-2 & 0.58 & 2- methylhexane & 2.32 & 1,3- methylethylbenzene & 1.57 \\
\hline penten-1 & 0.79 & 2,3-dimethylpentane & 0.66 & 1,4-methylethylbenzene & 0.56 \\
\hline trans-penten- 2 & 2.15 & 3- methylhexane & 2.13 & $1,3,5$ - trimethylbenzene & 0.75 \\
\hline cis-pentene-2 & 1.16 & 2- methylheptane & 1.01 & 1,2,4- trimethylbenzene & 2.53 \\
\hline 2-methylbutene-2 & 3.24 & 3- methylheptane & 0.99 & 1,2,3-trimethylbenzene & 0.52 \\
\hline tras-hexene-2 & 0.70 & 2-methyl-octane & 0.51 & 1,2-dimethyl-4- & \multirow[t]{2}{*}{0.51} \\
\hline 2- methylpenten-2 & 0.88 & 3.3-diethylpentane & 0.52 & ethylbenzene & \\
\hline 3-methyl-cis-pentene- 2 & 0.52 & methylcyclopentane & 2.51 & 5-methylindane & 0.58 \\
\hline 3,3-dimethylpentene-1 & \multirow[t]{2}{*}{0.84} & 1-methylcyclopentene & $\begin{array}{l}0.61 \\
0.68\end{array}$ & 2-methylindane & \multirow{2}{*}{$\begin{array}{l}0.56 \\
0.58\end{array}$} \\
\hline & & $\begin{array}{c}\text { 1-trans-3-dimethylcyciopentane } \\
\text { methylcyclohexane }\end{array}$ & $\begin{array}{l}0.08 \\
1.02\end{array}$ & naphthalene & \\
\hline \multicolumn{2}{|c|}{ Content in dry gas, $\%$ wt } & \multicolumn{2}{|l|}{ Content in PPF, \% wt } & \multicolumn{2}{|l|}{ Content in BBF, \% wt } \\
\hline & 2195 & & & n-butane & 8.9 \\
\hline Methane & $\begin{array}{l}21.95 \\
1945\end{array}$ & Propane & 17.98 & Isobutylene & 12.8 \\
\hline Ethane & $\begin{array}{l}19.45 \\
1906\end{array}$ & Propylene & 80.82 & Isobutane & 39.5 \\
\hline & 19.00 & & & Butylenes & 37.5 \\
\hline
\end{tabular}

The performed calculations using the quantum-chemical calculations and reference data made it possible to determine thermodynamically the most probable reactions of hydrocarbon formation $\mathrm{C}_{1}-\mathrm{C}_{4}$. Thermodynamic 
parameters of reactions leading to the formation of individual hydrocarbons of cracking gases are determined using The Density Functional Theory (DFT (B3LYP, basis 3-21G)) when hydrocarbons are absent in the reference data (* - the quantum-chemical calculations). Tables 4,5,6 show the thermodynamic parameters of the cracking reactions of alkanes and isoalkanes and alkenes of the gasoline with the formation of $\mathrm{C}_{1}-\mathrm{C}_{4}$ hydrocarbons.

TABLE 4. Thermodynamic parameters of cracking reactions of n-alkanes $C_{5}-C_{12}$ with the formation of hydrocarbons $C_{1}-C_{4}$.

(E)

TABLE 5. Thermodynamic parameters of cracking reactions of alkenes $C_{5}-C_{12}$ with the formation of hydrocarbons $C_{1}-C_{4}$.

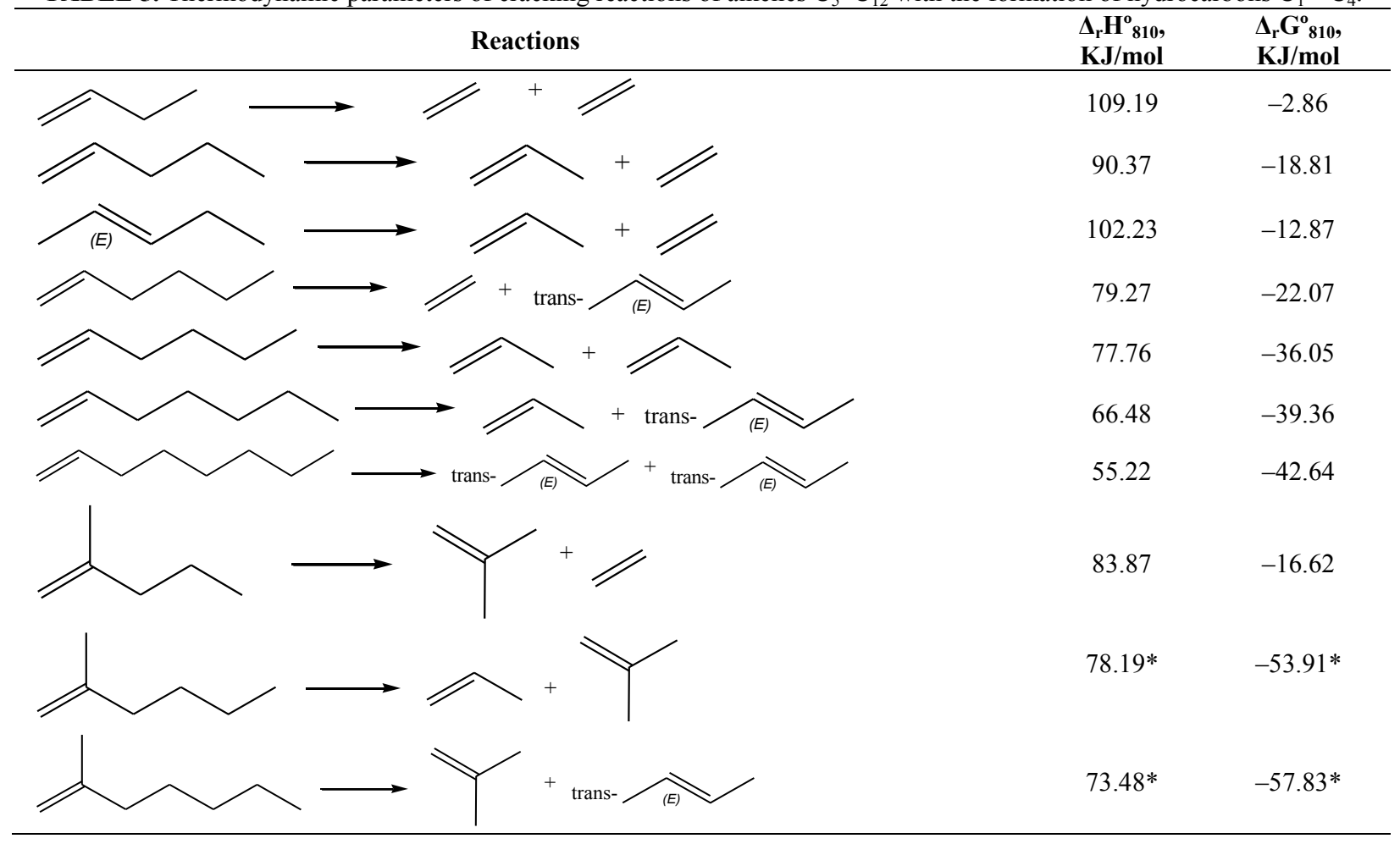

It is established that during the cracking of isoalkanes $(-47.13 \mathrm{~kJ} / \mathrm{mol}$ and $-40.38 \mathrm{~kJ} / \mathrm{mol})$ and alkenes $(-22.07$ $\mathrm{kJ} / \mathrm{mol}$ ) the formation of dry gas components - methane, ethane, and ethylene, respectively, is most probable 
according to reference data. For propane and propylene formation reactions, the most negative change takes place in Gibbs energy of isoalkanes and alkenes cracking reactions $(-40.23$ and $-39.36 \mathrm{~kJ} / \mathrm{mol})$. The formation of components of butylene fraction - n-butane, isobutane, isobutylene and butylene - is thermodynamically most likely for cracking alkanes $(-39.92 \mathrm{~kJ} / \mathrm{mol})$, isoalkanes $(-38.22$ and $-47.13 \mathrm{~kJ} / \mathrm{mol})$ and alkenes $(-42.64 \mathrm{~kJ} / \mathrm{mol})$.

TABLE 6. Thermodynamic parameters of cracking reactions of isoalkanes $\mathrm{C}_{5}-\mathrm{C}_{12}$ with the formation of hydrocarbons $\mathrm{C}_{1}-\mathrm{C}_{4}$.

(P)

In addition, we carried out the thermodynamic analysis of reactions of formation of cracking gases components during dealkylation of cycloalkanes and arenas of a gasoline fraction and reaction of hydrogen transfer (Table 7).

TABLE 7. Thermodynamic parameters of the reaction of dealkylation of arenas and cycloalkanes formation of hydrocarbons $\mathrm{C} 2-\mathrm{C} 4$.

Dealkilation of cycloalkanes $\mathbf{C}_{\mathbf{5}}-\mathbf{C}_{\mathbf{1 1}} \begin{gathered}\mathbf{\Delta}_{\mathbf{r}} \mathbf{H}_{\mathbf{8 1 0}}^{\mathbf{K} J / \mathbf{m o l}} \\ \mathbf{K J J}\end{gathered}$

The results of calculations showed that the reaction of cycloalkanes and arenas dealkylation with the formation of propylene ( -22.34 and $-11.69 \mathrm{~kJ} / \mathrm{mol})$ and butylene $(-26.45$ and $-14.45 \mathrm{~kJ} / \mathrm{mol})$, as well as the stage of hydrogen transfer with the formation of isobutans and arenas $(-146.67 \mathrm{~kJ} / \mathrm{mol})$, are characterized by high thermodynamic probability. 
The development of a scheme of hydrocarbons transformation, oriented on the prediction of individual composition of cracking gases

On the basis of established thermodynamic regularities, the formalized scheme of hydrocarbon transformations in the process of catalytic cracking [23], oriented on predicting the group composition of the gasoline fraction, the content of the PPF and BBF in rich gas and coke, is supplemented by reactions of the formation of individual components of cracking gases (highlighted in blue) (Fig. 2).

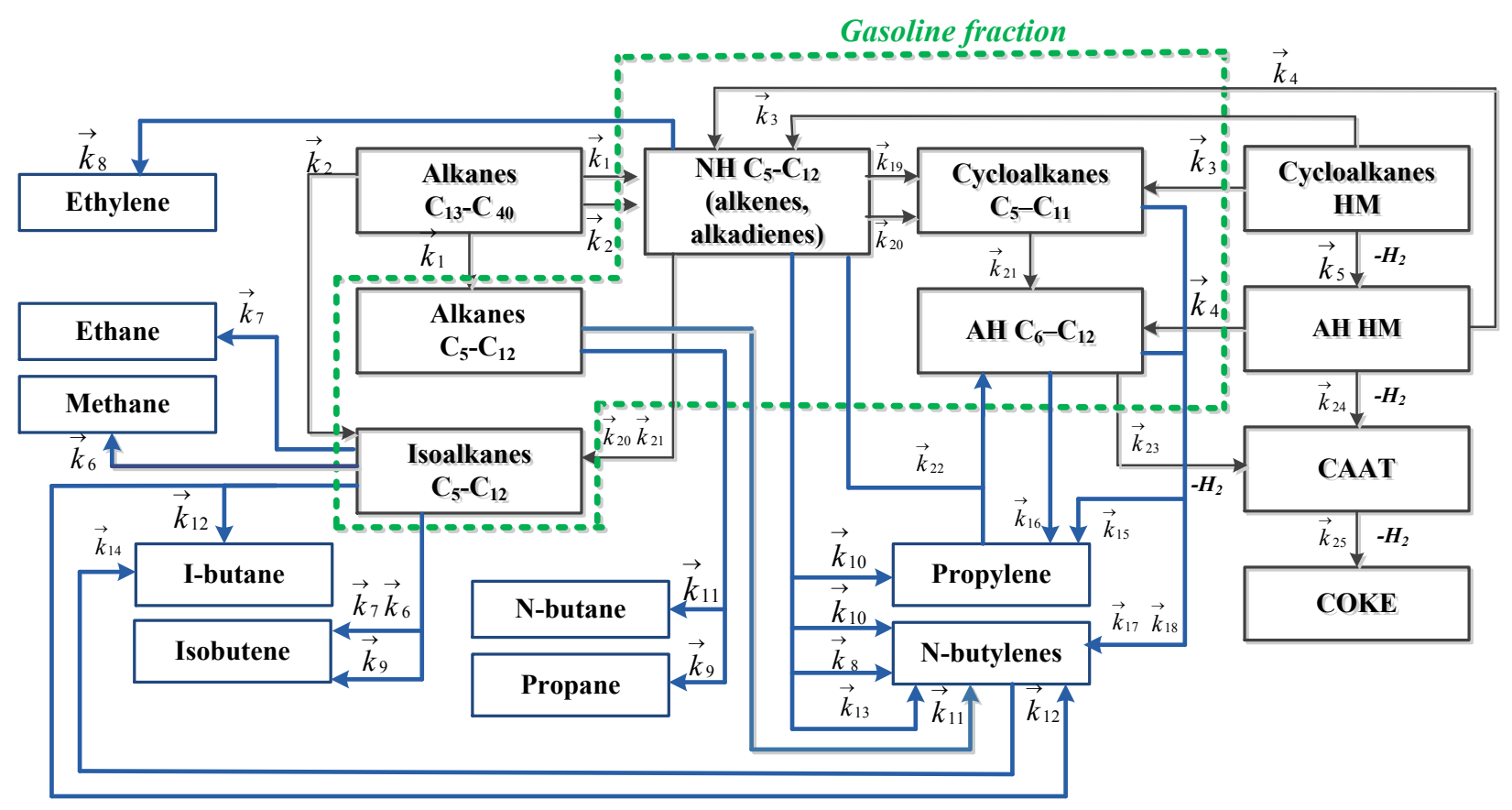

FIGURE 2. Formalized scheme of hydrocarbons transformations in the process of catalytic cracking at the temperature of the beginning of reaction $\left(810^{\circ} \mathrm{C}\right)$ - constants of the speed of direct chemical reactions.

Hydrocarbons are combined in accordance with their belonging to a certain class and their molecular weight, with the release of hydrocarbon groups of the gasoline fraction, coke and the individual composition of the gas. This scheme allows us to predict the content of these substances in products and to consider the catalyst activity changing depending of the coke amount.

The primary reactions are represented by cracking $\left(\mathrm{k}_{1}, \mathrm{k}_{2}, \mathrm{k}_{5}\right)$ and dealkylation $\left(\mathrm{k}_{3}, \mathrm{k}_{4}\right)$ of raw materials. Secondary cracking reactions are represented by dealkylation, cracking and isomerization reactions of arenas, cycloalkanes, alkanes, alkenes, isoalkanes of lower molecular weight with the formation of gas components $\left(\mathrm{k}_{6}-\mathrm{k}_{18}\right)$, which are valuable raw materials for the petrochemical industry, and hydrogen transfer $\left(\mathrm{k}_{20}, \mathrm{k}_{21}\right)$ with the formation of isoalkanes and arenas of the gasoline.

The formalized scheme takes into account the course of reactions leading to coking formation $\left(\mathrm{k}_{22}-\mathrm{k}_{25}\right)$, which provides the prediction of the amount of coke formed during the course of adverse reactions of cracking and catalyzed by heavy metals. As a result of the reactions of cracking, dealkylation, diene synthesis, cyclization, and hydrogen transfer, a significant number of alkenes and arenas are formed, which then form condensed structures during the course of condensation and coke formation reactions.

\section{CONCLUSION}

The characteristics and composition of the raw materials and products of the catalytic cracking process, as well as the established thermodynamic regularities of the reactions of the catalytic cracking process $\left(\Delta \mathrm{rG}^{\circ} 810=-(2.86-\right.$ 146.67) $\mathrm{kJ} / \mathrm{mol}$ ), are laid in the basis of a formalized scheme of transformations involving high-molecular hydrocarbons $\mathrm{C}_{13}-\mathrm{C}_{40}$. The scheme is aimed at predicting the yield and composition of the process products, including the group composition of the gasoline fraction, the individual composition of the coke cracking gases, and 
ensures the accounting of the group composition of raw materials. The selected level of formalization is confirmed by the mechanism of spontaneous chemical reactions under thermal conditions of catalytic cracking and provides flexibility and adequacy of the mathematical description of the industrial technology of catalytic cracking.

Development and application of a mathematical model with an extended scheme of transformation of hydrocarbons to cracking gases will provide predicting of the release and composition of cracking products (gasoline fraction and gases) depending on the composition of the raw material, the technological modes of operation of the devices and the activity of the catalyst. In the future, this will allow optimizing the work of coupled multistage processes of oil refining and petrochemistry, in particular, alkylation processes.

\section{ACKNOWLEDGMENTS}

This research was supported by Tomsk Polytechnic University CE Program

\section{REFERENCES}

1. Y. M. John, R. Patel and I. M. Mujtaba, Comp. Chem. Eng. 106, 730-743 (2017).

2. K. K. Dagde and Y. T. Puyate, IJERA 2 (6), 557-568 (2012).

3. E. D. Ivanchina, E. N. Ivashkina, V. A. Chuzlov, N. S. Belinskaya and A.Y. Dementyev, Chem. Eng. J. 383, 121283 (2020).

4. K. Xiong, Ch. Lu, Zh. Wang and X. Gao, Fuel 142, 65-72 (2015).

5. J. Corella and E. Francés, Fluid Catalytic Cracking II (American Chemical Society, ACS Symposium Series, Vol. 452, 1991), pp. 165-182.

6. Y. Qi et al., Appl. Math. Model. 40(21-22), 9378-9397 (2016).

7. L. Lee, Y. Chen, T. Huang and W. Pan, Can. J. Chem. Eng. 67, 615-619 (1989).

8. D. S. Stratiev et al., Pet. Sci. Technol. 34, 652-658 (2019).

9. A. A. Boitsova and N. K. Kondrasheva, J. Eng. Phys. Thermophys. 91(4), 1038-1046 (2018).

10. X. Kang, X. Guo and H. You, Energy Sources 35(20), 1921-1928 (2013).

11. S. Radu and D. Ciuparu, Rev. Chem. 65(1), 113-119 (2014).

12. S. M. Jacob, B. Gross, S. E. Voltz and V. W Jr. Weekman, AIChE Journal 22, 701-713 (1976).

13. J. Carella, Ind. Eng. Chem. Res. 43(15), 4080-4086 (2004).

14. L. Oliveira and E. C. Biscaia, Ind. Eng. Chem. Res. 28, 264-271 (1989).

15. J. Gao, C. Xu, S. Lin, G. Yang and Y. Guo, AIChE Journal 45, 1095-1113 (1999).

16. N. V. Dewachtere, G. F. Froment, I. Vasalos, N. Markatos and N. Skandalis, Appl. Therm. Eng. 17(8-10), 837-844 (1997).

17. N. V. Dewachtere, F. Santaella and G. F. Froment, Chem. Eng. Sci. 54, 3653-3660 (1999).

18. Y. Behjat, S. Shahhosseini, M. and Ahmadi Marvast, Chem. Eng. Res. Des.89 (7), 978-989 (2011).

19. M. Fakhroleslam and S. M. Sadrameli, Fuel 252, 553-566 (2019).

20. D. Stull, E. Westrum and G. Sinke, The Chemistry Thermodynamics of Organic Compounds (John Wiley \& Sons: New York, 1969).

21. E. D. Ivanchina, E. N. Ivashkina, and G.Y. Nazarova, Chem. Eng. J. 329, 262-274 (2017).

22. E. D. Ivanchina, E. N. Ivashkina, G. Y. Nazarova and G. Z. Seytenova, Petroleum Chemistry 58(3), 225236 (2018).

23. V. Chuzlov, G. Nazarova, E. Ivanchina, E. Ivashkina, I. Dolganova and A. Solopova, Fuel Process. Technol. 196, 106-139 (2019). 